\title{
ЛИТЕРАТУРОВЕДЕНИЕ
}

\author{
C. Зонтаг
}

\section{НАТАЛИ САРРОТ И РОМАН (Перевод Н. Г. Кротовской)}

Аннотация. Анализируя художественные и публицистические произведения Натали Саррот, автор проводит мысль о необходимости прогресса в искусстве. В отличие от других видов и форм искусства - поэзии, музыки, скульптуры и живописи - роман задержался в своем развитии, оставшись на позициях Х1Х века. В качестве примеров рассматриваются романы Пруста, Джойса, Вирджинии Вулф и других писателей, а также представителей франиузского «нового романа».

Ключевые слова: филология, искусство, современность, эволющия, роман, Саррот, психологический анализ, реальность, погружение, стиль.

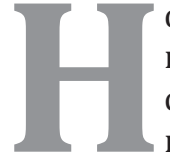

овый вид дидактизма, утвердившийся в гуманитарных науках, бесспорно, представляет собой «современный» элемент в искусстве. Его главная догма - мысль о том, что искусству надлежит эволюционировать. Его результат - произведение, главная цель которого сводится к развитию истории жанра, к техническому новаторству. Дух этого нового дидактизма превосходно выражен военизированными образами авангарда и арьергарда. Искусство - это армия, силами которой человеческая восприимчивость неумолимо продвигается к будущему, используя все более новые и более впечатляющие технические приемы. Это по большей части негативное отношение индивидуального таланта к традиции, положившее начало стремительному и неизбежному устареванию новых технических приемов и нового использования материалов, преодолело представление об искусстве, предлагающем знакомое удовольствие, и привело к возникновению множества произведений, преимущественно дидактических и назидательных. Теперь всякий знает, что цель картины Дюшана «Обнаженная, спускающаяся с лестницы» не столько что-либо изобразить - и менее всего обнаженную, спускающуюся с лестницы,- сколько преподать урок того, как можно разложить естественные формы на ряд кинетических планов. Цель прозаических работ Стайн и Беккета продемонстрировать, как могут быть преобразованы стиль речи, пунктуация, синтаксис и порядок повествования, чтобы выразить непрерывные безличные состояния сознания. Цель музыки Веберна и Булеза показать, как можно, например, развить ритмическую функцию тишины и структурную роль различных тембров звука.

Наиболее убедительную победу современный дидактизм одержал в музыке и живописи, где наибольшим уважением стали пользоваться произведения, доставляющие мало удовольствия при первом прослушивании или первом взгляде (если не считать узкой аудитории специалистов), но значительно продвинувшие вперед техническую революцию в этих областях искусства. По сравнению с музыкой и живописью роман, как и кино, безнадежно застрял в тылу. Подразделение «сложных» романов, сопоставимых с абстрактно-экспрессионистской живописью и musique concrete, не захватило территорию литературы, снискавшей уважение критиков. Напротив, бо́льшая часть отважных вылазок на передовую модернизма не увенчалась успехом. По прошествии нескольких лет они воспринимаются просто как единственные в своем роде произведения, однако отряды бойцов не следуют за храбрым командиром и не оказывают ему поддержки. Хвалебные отзывы критиков достаются романам, сопоставимым по сложности и достоинствам с музыкой Джан Карло Менотти и картинами Бернара Бюффе. Доступность и отсутствие ригоризма, смущающие в музыке и живописи, не вредят роману, который упорно плетется в арьергарде.

Однако нет жанра, более нуждающегося в пересмотре и обновлении - будь то в форме искусства для среднего класса или нет. Роман 


\section{Литературоведение}

(наряду с оперой) являет собой архетипическую форму искусства девятнадцатого века, великолепно выражающую исключительно земную концепцию реальности, с ее отсутствием понастоящему амбициозной одухотворенности, открытием «интересного» (то есть обыденного, несущественного, случайного, незначительного, преходящего) и утверждением того, что Чоран называет «судьбой с маленькой буквы». Роман, как неустанно нам напоминают все восхваляющие его критики и поносящие современные писатели-отступники, рисует человека-в-обществе; он вызывает к жизни кусок мира и помещает в этот мир «характеры». Разумеется, кто-то может считать роман наследником эпоса и плутовского романа. Однако всякий понимает, что это сходство поверхностно. Роман одушевляет нечто, напрочь отсутствовавшее в этих древних нарративных формах: открытие психологии, трансформация побуждений в «переживания». Эта страсть к документированию «переживания», к фактам, превратила роман в наиболее открытую из всех форм искусства. Любые формы искусства имлицитно используют стандарты того, что считать высоким, а что низким - за исключением романа. Он может вместить любой уровень языка, любой сюжет, любые идеи, любую информацию. И это в итоге погубило его как серьезную форму искусства. Рано или поздно пристрастные читатели должны были утратить интерес к очередному неспешному «рассказу», к очередному десятку частных жизней, выставленных на показ. (Они обнаружили, что кино делает это с бо́льшей свободой и убедительностью). В то время как музыка, пластические искусства и поэзия мучительно освобождались от устаревших догм «реализма» девятнадцатого века, обнаруживая страстную приверженность идее прогресса в искусстве и лихорадочно отыскивая новый стиль и новые материалы, роман оказался неспособным ассимилировать любые формальные и духовные притязания, осуществленные в его честь в двадцатом веке. Он опустился до уровня формы искусства, глубоко - если не безвозвратно - скомпрометировавшей себя союзом с филистерством.

Когда вспоминаешь о таких гигантах, как Пруст, Джойс, Жид в «Подземельях Ватикана», Кафка, Гессе в «Степном волке» и Жене или о менее крупных, но превосходных писателях, таких, как Машаду де Ассиз, Свево, Вулф, Стайн, ранний Натаниэл Уэст, Селин, Набоков, ранний Пастернак, Джуна Барнс в «Ночном лесе», Беккет (если упо- мянуть лишь некоторых), то вспоминаешь о писателях, лишь подошедших к открытию новой формы - у них нечему учиться, им невозможно подражать, ибо подражание несет в себе опасность простого повтора того, что ими уже сделано. Не знаешь, ругать или хвалить критиков за то, что происходит с этой формой искусства - во благо или во вред. Однако трудно не прийти к заключению, что роману как раз не удалось окончательно дистанцироваться от предпосылок девятнадцатого века и что ему необходимо это сделать, если он собирается неизменно (а не спорадически) оставаться серьезным видом искусства. (Пышный расцвет литературной критики в Англии и Америке, возникший тридцать лет назад сначала с критики поэзии, а затем и романа, отнюдь не повлек за собой подобной переоценки. Эта философски наивная критика слепо принимает "реализм», не задаваясь вопросом о его престиже).

Совершеннолетие романа повлечет за собой приверженность разного рода спорным понятиям наподобие идеи «прогресса» в искусстве и неприкрыто агрессивную идеологию, выраженную в метафоре авангарда. Это ограничит круг читателей романа, ибо потребует от них признать новые удовольствия, получаемые от беллетристики вроде удовольствия решать проблемы,- и овладеть наукой их получать. (К примеру, это может означать, что нам придется читать не только про себя, но и вслух, и, несомненно, будет означать, что нам понадобится не раз перечитать роман, чтобы понять его до конца или почувствовать себя вправе о нем судить. Мы уже не возражаем против того, чтобы несколько раз читать, смотреть или слушать серьезную современную поэзию, живопись, скульптуру или музыку). И все, кому захочется серьезно заняться формой, намеренно станут эстетами, требовательными исследователями. (Все «современные» художники эстеты). Этот отказ от непременной легкости романа, необременительной доступности и сохранения устаревшей эстетики, несомненно, вызовет к жизни множество скучных и претенциозных книг; и кто-то захочет вернуться к прежней простоте. Но эту цену придется заплатить. Новое поколение критиков должно убедить читателей в необходимости такого шага, принудив их принять этот непривлекательный период развития романа с помощью разнообразной соблазнительной и временами не слишком честной риторики. И чем скорее это случится, тем лучше.

Пока у нас существует непрерывная серьезная «современная» традиция романа, дерзкие 


\section{Филология: научные исследования 4(12) • 2013}

романисты будут работать в вакууме. (Неважно, назовут ли критики такую прозу романом или нет. Терминология не стала препятствием в живописи, музыке или поэзии, хотя мы склонны заменять слово «скульптура» такими словами, как «конструкция» или «ассамблаж»). В нашем пейзаже, подобно брошенным танкам, по-прежнему будут выситься чудовищные громады. Примером - пожалуй, величайшим примером служат «Поминки по Финнегану», до сих пор большей частью непрочитанные и нечитабельные, оставленные на откуп академическим толкователям, которые способны расшифровать для нас книгу, но не способны объяснить, почему мы должны ее читать или чему она нас может научить. Требование Джойса, рассчитанное на то, что читатели посвятят его книге всю жизнь, может показаться чрезмерным; но если принять во внимание уникальность его произведения, представляется логичным. К тому же, судьба последней книги Джойса обусловила слепое принятие менее громоздких, но также лишенных фабулы произведений, впоследствии появившихся в Англии - вспомнить хотя бы книги Стайн, Беккета и Берроуза. Неудивительно, что на поле боя, где воцарилась зловещая тишина, последние представляются отдельными безуспешными вылазками.

Однако затем ситуация, похоже, начала меняться. Целая школа - не лучше ли сказать батальон? - важных и многообещающих романов появилась во Франции. Здесь перед нами по сути два крыла. Во главе первого стояли Морис Бланшо, Жорж Батай и Пьер Клоссовски; бо́льшая часть их книг была написана в 1940-х годах и до сих пор не переведена на английский. Более известны, и в основном переведены, книги «второй волны», написанные в 1950-х (среди прочих) Мишелем Бютуром, Аленом Роб-Грийе, Клодом Симоном и Натали Саррот. Всех этих писателей, весьма непохожих друг на друга по своим намерениям и успеху, объединяет нечто общее: они отрицают идею «романа», задача которого рассказать историю и очертить характеры в соответствии с правилами реализма XIX века; к тому же, все они отрекаются от того, что можно обозначить словом «психология». Пытаются ли они выйти за рамки психологии с помощью хайдеггеровской феноменологии (могучее влияние) или подсечь ее с помощью бихевиористского, внешнего описания, они достигают схожих результатов - по меньшей мере, отрицательных,- полагая за основу произ- ведения форму романа, что обещает сообщить нам нечто полезное о новых формах, которые способна принимать литература.

Возможно, самое ценное достижение в области романа, пришедшее из Франции - это множество критических работ, вдохновленных новыми романистами (и в некоторых случаях написанных ими), которые можно назвать самой впечатляющей попыткой систематических размышлений об этом жанре. Эти работы - я имею в виду эссе Мориса Бланшо, Ролана Барта, Э. М. Чорана, Алена Роб-Грийе, Натали Саррот, Мишеля Бютора, Мишеля Фуко и других - сегодня являются самой интересной литературной критикой. И ничто не мешает романистам в англо-говорящем мире воспользоваться блестящим пересмотром предпосылок романа в изложении этих авторов, однако работать над романом совершенно иначе, чем французы. Эти эссе могут оказаться ценнее самих романов по той причине, что в них предлагаются более широкие и более амбициозные стандарты, чем те, что достигнуты в произведениях любого писателя. (К примеру, Роб-Грийе признается, что его романы - неадекватная иллюстрация диагнозов и рекомендаций, изложенных в его эссе).

Вот почему, на мой взгляд, важно, чтобы сборник эссе Натали Саррот «Эра подозрения», в котором полностью изложена теория, будто бы лежащая в основе ее романов ${ }^{1}$, вышел на английском языке. Неважно, любите ли вы романы Саррот, восторгаетесь ими или нет (лично мне по-настоящему нравятся только «Портрет неизвестного» и «Планетарий»), неважно, действительно ли она осуществляет то, что проповедует (сказать по правде, я думаю, что нет), в этих эссе предлагается критика традиционного романа, которая, на мой взгляд, могла бы послужить хорошим началом для теоретического пересмотра, сильно запоздавшего по эту сторону Атлантики.

Возможно, наилучшим подходом для англоговорящего читателя было бы сопоставление полемики Саррот с двумя другими манифестами о том, каким надлежит быть роману - «Мистер Беннет и миссис Браун» Вирджинии Вулф и «Факт в литературе» Мэри Маккарти. Отказ Вирджинии Вулф от натурализма и объективного реализма, ее призыв к современным писателям исследовать «темные тайники психологии»². Саррот отвергает

${ }^{1}$ Sarrot Natalie. The Age of Suspicion. New York, Braziller. (Перевод Марии Джолас).

2 Здесь и далее цитируется по книге: Саррот Н. Тропизмы. 


\section{Литературоведение}

как «наивный». Не менее строга она к позиции, представленной в эссе Мэри Маккарти, которую можно рассматривать как опровержение взглядов Вирджинии Вулф, к позиции, открыто призывающей вернуться к прежним романическим доблестям: изображать реальный мир, создавать ощущение правдоподобия и придумывать незабываемые характеры.

Аргументы Саррот, выдвинутые против реализма, убеждают. Реальность не столь определенна; жизнь не столь жизнеподобна. Немедленное и незатруднительное узнавание жизнеподобного в большинстве романов, вызывает - и должно вызывать - подозрение. (Бесспорно, миром, как говорит Саррот, овладел дух подозрения. А если не дух, то, по меньшей мере, неизлечимый порок). Я искренне поддерживаю ее возражения против отжившего свой век романа: «Ярмарка тщеславия» и «Буденброки», когда я их перечитала, какими бы великолепными они мне и теперь ни показались, заставили меня поморщиться. Я не могла смириться с тем, что всемогущий автор показывает мне, какова на самом деле жизнь, заставляя меня сострадать и лить слезы; не могла смириться с его необузданной иронией, с той убежденностью, с какой он внушает мне, что близко знаком со своими героями, заставляя меня, читателя, почувствовать, что я тоже с ними знакома. Я более не доверяю романам, которые сполна удовлетворяют мою страсть к пониманию. Саррот права и в том, что обветшалая машинерия, используемая для обстановки какой-либо сцены, для описания и развития характеров, не оправдывает себя. Кого, в сущности, интересует мебель в комнате такогото, курил ли он сигарету, носил ли темно-серый костюм, открыл ли крышку пишущей машинки после того, как сел, и перед тем, как вставил с нее лист бумаги? Великие фильмы показали, что кино умеет наделять чисто физическое действие мимолетное и незначительное, как смена парика в «Приключении», или важное, как марш по лесу в «Большом параде» - большей магией, чем это делают слова, и к тому же, меньшими средствами.

Однако более сложным и проблематичным является утверждение Саррот о том, что психологический анализ в романе в равной мере устарел и вводит в заблуждение. «Слово «психология»,- говорит Саррот,- - ни один современный писатель не может слышать, не опустив глаза и не покраснев». Под психологией в романе она

Эра подозрения. М.: Полинформ-Талбури, 2000. понимает Вулф, Джойса, Пруста: романы, исследующие субстрат тайных мыслей и чувств, лежащих в основе действия, описание которых вытесняет внимание к литературному герою и сюжету. Единственное, что Джойс поднял на поверхность из этих глубин, замечает она, это непрерывный поток слов. Пруст также потерпел поражение. В конце концов мельчайшие частицы, полученные Прустом в результате психологического вскрытия, сами по себе складываются в реалистические характеры, в которых опытный глаз читателя «тотчас признал бы богатого светского человека, влюбленного в содержанку, преуспевающего медика, глупца и невежу, буржуа-выскочку или высокомерную светскую даму, объединенных в обширную коллекцию романтических персонажей в его воображаемом музее».

В действительности романы Саррот не так уж сильно, как она полагает, отличаются от романов Джойса (и Вулф), а ее отрицание психологии, далеко не полно. Она стремится именно к психологическому, но (и в этом основа ее недовольства Прустом) без возможности возвращения назад к «характерам»и «сюжету». Саррот выступает против психологического вскрытия, ибо оно предполагает наличие тела, которое требуется вскрыть. Она против условной психологии, против психологии как нового средства достижения старых целей. Против использования психологического микроскопа время от времени, лишь в качестве средства развития сюжета. Это означает радикальную перестройку романа. Писатель должен не только не рассказывать историю; он должен не отвлекать читателя важными событиями вроде убийства или большой любви. Чем более мелкими, менее сенсационными будут события, тем лучше. (Так роман «Мартеро»состоит из размышлений безымянного молодого человека, дизайнера интерьеров, об артистичной тетушке, богатом бизнесмене дядюшке, с которыми он живет, и пожилом, не столь состоятельном человеке по имени Мартеро, размышлений о том, почему и при каких обстоятельствах ему приятно находиться в их компании, а также почему и когда он чувствует, что поддается влиянию их личностей и окружающих их предметов. Единственным «действием»книги является намерение тетушки и дядюшки купить загородный дом, и если на какое-то время возникает подозрение, что Мартеро обманывает дядю в вопросе с покупкой дома, то можно не сомневаться, что в конце все подозрения рассеются. В «Планетарии» нечто все же 


\section{Филология: научные исследования 4(12) • 2013}

происходит. Честолюбивому молодому человеку, беззастенчиво пытающемуся пробиться в круг общения богатой, самодовольной и очень известной женщины-писательницы, в конце концов удается отнять пятикомнатную квартиру у своей доверчивой престарелой тетушки). Однако персонажи Саррот никогда не действуют по-настоящему. Они строят планы, они трепещут, они содрогаются под действием мелочей повседневной жизни. Истинной темой ее романов является эта подготовка и осторожный поиск действия. Поскольку анализ - то есть повествование и толкование от лица автора - отброшен, романы Саррот, естественно, пишутся от первого лица, даже когда внутренняя необходимость заставляет ее использовать местоимения «она» или «он».

То, что предлагает Саррот - это роман, написанный в форме непрерывного монолога, в котором диалог между персонажами служит функциональным дополнением монолога, «реальная» речь - продолжением речи про себя. Она называет этот вид беседы «под-разговором». Его можно сравнить с театральный диалогом, происходящим без авторского вмешательства и толкования, однако в отличие от последнего не разделенного на части и не приписанного отдельным персонажам. (Она употребляет чрезвычайно едкие насмешливые словечки по поводу скрипучих «он сказал», «она ответила», «такой-то заявил», которыми пересыпано большинство романов). Роману нужен диалог «сотрясаемый и раздуваемый этими движениями, которые лежат в его основе и двигают вперед». Роману следует отречься от методов классической психологии - анализа - и вместо этого обратиться к погружению. Он должен погрузить читателя «в поток тех подспудных драм, которые Пруст имел время лишь бегло очертить и которые он наблюдал [с высоты] и воспроизводил лишь в виде широких неподвижных линий». Роман должен регистрировать без комментариев прямой и чисто сенсорный контакт с вещами и людьми, который испытывает «Я» писателя. Воздерживаясь от создания всякого подобия (Саррот оставляет это кинематографу), роман должен сохранить и усилить «ту часть неопределенности, ту непрозрачность и таинственность, которую всегда имеют эти действия для того, кто за ними наблюдает».

В программе, предложенной Саррот для романа, есть нечто вселяющее бодрость, ибо в ней утверждается безграничное уважение к сложности человеческих чувств и ощущений. Однако, на мой взгляд, ее аргументация грешит некоторой мягкостью, основанной к тому же на крайне доктринерском и одновременно двусмысленном понимании психологии. Точка зрения, согласно которой «старания Генри Джеймса или Пруста разобрать хрупкие винтики наших внутренних механизмов» уподобляются работе киркой и лопатой, воистину являет блестящий уровень психологической утонченности. Кто станет возражать Саррот, когда она описывает чувства как огромную подвижную массу, в которой можно обнаружить что угодно; или когда говорит, что все ее движения не может объяснить ни одна теория, и менее всего некий код, наподобие психоанализа? Однако Саррот нападает на психологию в романе во имя лучшей, более совершенной техники психологического описания.

Ее взгляды на сложность чувств и ощущений - это одно, другое дело ее программа по реформированию романа. Все описания мотивации, бесспорно, страдают упрощением. Но даже если это так, у писателя, помимо поиска более утонченного способа изображения мельчайших побуждений, остается множество других возможностей. К примеру, определенные виды общего впечатления - напрочь исключающие описание мельчайших оттенков чувств,- на мой взгляд, предлагают, по меньшей мере, столь же действенное решение поднимаемой Саррот проблемы, как и совершенствование техники диалога и повествования, выдаваемое ею за логическое следствие своей критики. Возможно, характер - это (как настаивает Саррот) океан, место слияния водяных потоков, течений и водоворотов, однако преимущество погружения мне не очевидно. Подводное плавание имеет место, но есть еще океаническая картография, которую Саррот презрительно отвергает как «взгляд с высоты». Человек - существо, которому предначертано жить на поверхности; он селится в глубинах - земных, океанских или психологических - себе на погибель. Я не разделяю презрения Саррот к попыткам писателя преобразовать водянистые бесформенные глубины опыта в твердое вещество, зафиксировать его очертания, придать миру определенную форму и объем, воспринимаемые чувствами. Само собой разумеется, делать это прежним способом скучно. Но я не соглашусь, что это невозможно сделать вовсе. Саррот призывает писателя сопротивляться желанию развлекать, менять и поучать своих современников или бороться за их освобождение; он должен просто, без прикрас, не смягчая и не прео- 


\section{Литературоведение}

долевая противоречий, представить «реальность» (слово, употребленное Саррот) такой, какой ее видит, с той искренностью и остротой зрения, на которую способен. Здесь я не стану обсуждать вопрос о том, должен ли роман развлекать, менять или поучать (почему бы и нет, коль скоро он произведение искусства?), лишь укажу на то, насколько предвзято предлагаемое ею определение реальности. Реальность для Саррот означает реальность, освобожденную от «шелухи предвзятых идей и избитых образов». Она противостоит «поверхностной реальности, которую любой замечает без труда и которой каждый пользуется за неимением лучшего». По мнению Саррот, писатель, чтобы установить контакт с реальностью, должен «добраться до чего-то еще неизвестного, что, как ему кажется, в первую очередь достойно внимания».

Но какова цель этого умножения реальностей? Ибо, по правде говоря, Саррот следовало бы употребить множественное, а не единственное число. Если каждый писатель «должен вытащить на свет свою часть реальности» - поскольку все киты и акулы уже занесены в каталог, она охотится за новой разновидностью планктона,писатель оказывается не только творцом таких частей, но обречен описывать лишь то, что коренится в его собственной субъективности. Когда он выходит на литературное поприще, неся в руках сосуд с образцами микроскопических морских организмов, еще не занесенных в каталог, должны ли мы приветствовать его во имя науки? (Писатель как морской биолог). Или спорта? (Писатель как глубоководный ныряльщик). Достоин ли он аудитории? Сколько частей реальности необходимо читателям романов?

Обращаясь к понятию реальности как таковой, Саррот на деле сузила и обеднила свои доказательства, безо всякой на то необходимости. Метафору произведения искусства как отражения реальности следует на время оставить. Она в свое время сослужила службу при анализе произведений искусства, но сегодня вряд ли поможет нам ответить на важные вопросы. Результат рассуждений Саррот неутешителен она продлевает жизнь унылым альтернативам субъективности в противовес объективности, оригинального в противовес уже сложившемуся и готовому. Неясно, почему при помощи новых средств писатель не может преобразовать то, что всем уже известно, при этом ограничившись как раз сложившимися представлениями и готовыми образами.
Приверженность Саррот довольно бессодержательному понятию реальности (реальности, скорее, лежащей в глубине, чем на поверхности) также объясняет излишне суровый тон ее увещеваний. Ее холодный отказ признать за писателем право дарить своим читателям «эстетическое удовольствие» чисто риторичен и глубоко несправедлив к той позиции, талантливой представительницей которой она отчасти является. Писатель, говорит она, должен подавить в себе «всякое стремление пользоваться хорошим стилем просто ради удовольствия это делать, ради того, чтобы доставить себе и читателям эстетическое удовольствие». Стиль «может быть красивым лишь в том смысле, в каком красив жест атлета: тем красивее, чем лучше служит он своей цели». Напомним, цель автора - зафиксировать восприятие незнакомой реальности. Однако нет никакой причины приравнивать «эстетическое удовольствие», которое по определению должно доставлять любое произведение искусства, с понятием поверхностного, декоративного, всего лишь «красивого» стиля... За образец романа Саррот на самом деле принимает науку или, вернее, спорт. Окончательным оправданием поисков писателя, как их определяет Саррот - того, что, на ее взгляд, освобождает роман от всех моральных и социальных целей,- служит стремление к истине (или ее части), как в науке, а также профессиональный тренинг, как в спорте. В принципе, такие образцы не вызывают возражений, если бы не значение, которое им придает Саррот. Несмотря на всю обоснованность ее критики устаревшего романа, она по-прежнему считает, что писатель должен заниматься поисками «истины»и «реальности».

Таким образом, в итоге можно заключить, что манифест Саррот дает незаслуженно заниженную оценку позиции, которую она защищает. Более точное и более глубокое описание этой позиции можно найти в сборниках эссе РобГрийе «О нескольких устаревших понятиях» и «Природа, гуманизм, трагедия». Они появились соответственно в 1957 и 1958 годах, тогда как работы Саррот, опубликованные между 1950 и 1955 годами, вышли книгой в 1956; к тому же, Роб-Грийе цитирует Саррот таким образом, что можно принять его за последующего выразителя той же позиции. Однако сложная критика понятий трагедии и гуманизма, предложенная Роб-Грийе, неизменная ясность, с которой он опровергает избитое противопоставление формы содержанию 


\section{Филология: научные исследования 4(12) • 2013}

(к примеру, его готовность заявить, что роман, коль скоро он принадлежит к сфере искусства, не имеет содержания), совместимость его эстетики с техническими инновациями в области романа, совершенно иными, чем избранные им самим, ставят его аргументацию на гораздо более высокий уровень, чем у Саррот. Эссе Роб-Грийе понастоящему радикальны и, если принять хотя бы одно из его допущений, звучат убедительно. Эссе Саррот, помогающие ввести образованного англо-говорящего читателя в круг появившейся во Франции серьезной критики традиционного романа, в итоге не дают прямых ответов и ведут к компромиссу.

Несомненно, многие почувствуют, что перспективы развития романа, намеченные француз- скими критиками, довольно безрадостны; этим людям захочется, чтобы отряды искусства попрежнему сражались на других фронтах, оставив роман в покое. (Так, некоторым из нас хотелось бы иметь гораздо менее мучительное психологическое самосознание, лежащее тяжким бременем на образованных людях нашего времени). Однако роман как форма искусства нечего не потеряет и многое приобретет, присоединившись к революции, которая уже разразилась в большинстве других видов искусства. Для романа настало время стать тем, чем он, за редким исключением, не является ни в Англии, ни в Америке: формой искусства, которую люди со строгим взыскательным вкусом могут воспринимать всерьез.

[1963; переработано в 1965].

\section{Список литературы:}

Zontag S. Against Interpretation and Other Essays. N.Y.: Farrar, Straus and Giriox, 1966.

\section{References (transliteration):}

Zontag S. Against Interpretation and Other Essays. N.Y.: Farrar, Straus and Giriox, 1966. 